\title{
Calcium-permeable AMPA receptors in the retina
}

\author{
Jeffrey S. Diamond* \\ Synaptic Physiology Section, National Institute of Neurological Disorders and Stroke, National Institutes of Health, Bethesda, MD, USA
}

Edited by:

R. Suzanne Zukin, Albert Einstein

College of Medicine, USA

\section{Reviewed by:}

Juan Lerma, Instituto de

Neurociencias, Spain

Frantisek Jursky, Slovak Academy of

Sciences, Slovak Republic

*Correspondence:

Jeffrey S. Diamond, Synaptic

Physiology Section, National Institute of Neurological Disorders and Stroke,

National Institutes of Health, 35

Convent Drive, Building 35, Room

3C-1000, Bethesda, MD 20892-3701,

USA.

e-mail: diamondj@ninds.nih.gov
The retina transforms light entering the eye into a sophisticated neural representation of our visual world. Specialized synapses, cells, and circuits in the retina have evolved to encode luminance, contrast, motion, and other complex visual features. Although a great deal has been learned about the cellular morphology and circuitry that underlies this image processing, many of the synapses in the retina remain incompletely understood. For example, excitatory synapses in the retina feature the full panoply of glutamate receptors, but in most cases specific roles for different receptor subtypes are unclear. In this brief review, I will discuss recent progress toward understanding how $\mathrm{Ca}^{2+}$-permeable AMPA receptors (CP-GluARs) contribute to synaptic transmission and newly discovered forms of synaptic plasticity in the retina.

Keywords: apoptosis, TARP, vision, polyamine, review, ganglion cell, receptor trafficking, feedback

\section{BRIEF OVERVIEW OF RETINAL CIRCUITRY}

The vertebrate retina is a beautifully laminar structure comprising five major neuronal cell types (Figure 1). Photons are absorbed by rod and cone photoreceptors, which transduce light energy into a neural signal that is transmitted to bipolar cells. Nine types of bipolar cell in the mammalian retina receive their input from cones (Wassle et al., 2009); a tenth type, the rod bipolar cell (RBC), receives its input from rods. Cone bipolar cells make excitatory synapses directly onto ganglion cells (GCs), whereas RBCs contact AII (A2) amacrine cells, which relay the ON signal from the RBC to $\mathrm{ON}$ and OFF cone bipolar cell terminals via sign-conserving (electrical) and sign-inverting (glycinergic) synapses, respectively. This excitatory pathway is modulated by two laterally oriented, inhibitory networks. In the outer retina, horizontal cells provide feedback to generate the first center-surround receptive fields in the visual pathway; several dozen amacrine cell types in the inner retina provide feedback and feedforward inhibition that sharpens the temporal properties of visual signaling and contributes to more complex visual processing. In the mammalian retina, only GCs, whose axons are bundled together in the optic nerve, and some amacrine cells fire action potentials. Most synapses transmit ana$\log$ information via relatively small, graded changes in membrane potential. Presynaptic active zones in photoreceptors (Figure 1B) and bipolar cells (Figure 1C) have evolved "ribbon" structures that are thought to regulate the delivery of synaptic vesicles to release sites and thereby sustain ongoing transmitter release (Parsons and Sterling, 2003).

\section{CP-GLUAR EXPRESSION IN RETINAL NEURONS}

Cells expressing functional CP-GluARs can be identified by a procedure that stains cobalt $\left(\mathrm{Co}^{2+}\right)$, a divalent cation that permeates the CP-GluAR pore (Pruss et al., 1991). First, the tissue is stimulated with a GluAR agonist added to extracellular solution containing $\mathrm{CoCl}_{2}$, then rinsed in solution containing $\left(\mathrm{NH}_{4}\right)_{2} \mathrm{~S}$, which reacts with the intracellular $\mathrm{Co}^{2+}$ to form $\mathrm{CoS}$ precipitate. Silver enhancement stains the precipitate a deep amber, clearly identifying $\mathrm{Co}^{2+}$-loaded cells (Figure 1D). When $\mathrm{CoCl}_{2}$ is applied to retinal slices in the presence of NMDA receptor antagonists, the consequent $\mathrm{CoS}$ precipitation is blocked completely by GluAR antagonists and, except in special cases (discussed below), polyamine antagonists of CP-GluARs, indicating specific labeling of CP-GluAR-expressing cells (Osswald et al., 2007).

In the embryonic chick retina, the CP-GluAR-specific $\mathrm{Co}^{2+}$ staining technique robustly labels horizontal cells, amacrine cells, and GCs (Allcorn et al., 1996), consistent with reported CPGluAR-mediated currents in cells dissociated from embryonic chick retina (Catsicas et al., 2001) and $\mathrm{Ca}^{2+}$ imaging experiments showing agonist-activated $\mathrm{Ca}^{2+}$ in the outer plexiform layer (OPL), inner plexiform layer (IPL), and GC layer (GCL; Sugioka et al., 1998). Similar $\mathrm{Co}^{2+}$ staining patterns are observed in the juvenile rat retina (Figure 1B; Leinders-Zufall et al., 1994; Osswald et al., 2007). GC staining in rat decreases substantially following eye opening (P14; Figure 1E; Osswald et al., 2007), but GCs isolated from neonatal rat retina exhibit CP-GluAR-mediated currents (Rorig and Grantyn, 1993; Leinders-Zufall et al., 1994; Zhang et al., 1995; Otori et al., 1998) and $\mathrm{Ca}^{2+}$ signals (Leinders-Zufall et al., 1994; Otori et al., 1998).

Although CP-GluAR-mediated currents have been reported in cat bipolar cells (Sasaki and Kaneko, 1996), the large majority of work has been focused on horizontal cells, amacrine cells, and GCs. The remainder of this review will highlight the distinct, interesting roles that CP-GluARs play in each of these cell types.

\section{CP-GLUARS IN HORIZONTAL CELLS MEDIATE POSITIVE FEEDBACK ONTO PHOTORECEPTORS}

Functional CP-GluARs have been found in horizontal cells of every species investigated, including lizard (Jackman et al., 2011), fish (Eliasof and Jahr, 1997; Huang and Liang, 2005; Sun et al., 

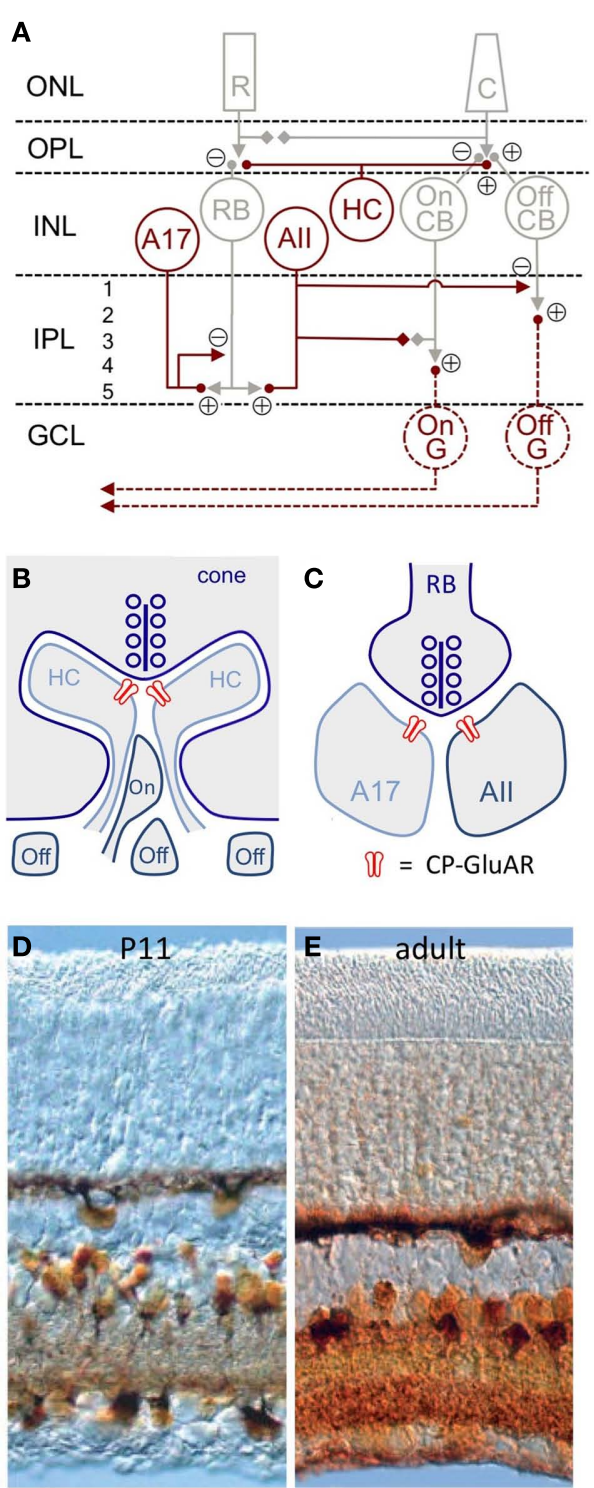

FIGURE 1 | CP-GluAR expression in the retina. (A) Schematic of mammalian retina (Naney et al., 1991). CP-GluAR + cell types are highlighted in amber; GCs are hatched because the express CP-GluARs primarily early in development. $\mathrm{R}$, rod; $\mathrm{C}$, cone; $\mathrm{RB}$, rod bipolar cell; $\mathrm{HC}$, horizontal cell; $\mathrm{CB}$, cone bipolar cell; $\mathrm{G}$, ganglion cell; $\mathrm{ONL}$, outer nuclear layer; $\mathrm{OPL}$, outer plexiform layer; INL, inner nuclear layer; IPL, inner plexiform layer; GCL, ganglion cell layer. (B) Schematic showing triad synapse in the OPL between presynaptic cone photoreceptors and postsynaptic horizontal cells and bipolar cells. Modified from DeVries (2000). (C) Schematic showing dyad synapse in IPL between presynaptic rod bipolar cell and postsynaptic A17 and All amacrine cells. In (B,C) CP-GluARs are indicated in red. (D) $\mathrm{Co}^{2+}$ staining in the $\mathrm{P} 11$ rat retina shows functional CP-GluAR expression in horizontal cells, amacrine cells, and ganglion cells (Osswald et al., 2007). (E) CP-GluAR expression is reduced in adult ganglion cells (Osswald et al., 2007).

2010), skate (Kreitzer et al., 2009), and rabbit (Rivera et al., 2001; Figure 1B). Catfish cone horizontal cells, stellate neurons with enormous somata (Sakai and Naka, 1986), express extraordinarily fast CP-GluARs: in excised membrane patches at room temperature, glutamate-evoked currents desensitized with a time constant of $\sim 1 \mathrm{~ms}$ and recovered from desensitization with a time constant of less than $9 \mathrm{~ms}$ (Eliasof and Jahr, 1997). These rapid kinetics, rivaled only by GluARs receptors in avian auditory nuclei (Raman and Trussell, 1992), suggest that CP-GluARs may mediate local signaling in horizontal cell processes, because such brief conductances would be filtered strongly by the large membrane capacitance of the cell.

Local signaling in horizontal cells has long been known to mediate negative feedback onto photoreceptors, but the identity of the underlying mechanism remains controversial (Kamermans et al., 2001; Hirasawa and Kaneko, 2003; Hirano et al., 2005; Vessey et al., 2005). A recent report has introduced an intriguing wrinkle by providing evidence for positive feedback signaling onto cone photoreceptors that involves CP-GluARs on horizontal cells (Jackman et al., 2011). Vesicle release was measured from cone photoreceptors in lizard retinal slices (anole lizards express only cone photoreceptors) using the membrane dye FM1-43. Applied through the superfusion solution, FM1-43 integrates into membranes and is taken up into presynaptic terminals via membrane endocytosis. When FM1-43 is washed from the extracellular solution, fluorescent vesicles remain in the presynaptic terminal until released. Cones release synaptic vesicles constantly in the dark, and so the FM1-43 signal in cone terminals decayed steadily following loading. The authors found, surprisingly, that exogenous glutamate application accelerated FM1-43 destaining (i.e., vesicle release) in cone terminals (Jackman et al., 2011). This effect was mimicked by AMPA and blocked by CP-GluAR receptor antagonists, despite the fact that cones express no functional GluARs. Accelerated release was observed only in thick slices, suggesting a role for laterally oriented neurons like horizontal cells. Accordingly, laser ablation of horizontal cells eliminated AMPA-induced accelerated release. These results suggested that activation of CP-GluARs on horizontal triggers some feedback signal to enhance release from cones. Depolarizing horizontal cells only diminished release from cones, however, likely reflecting the previously described negative feedback. Instead, release from cones was accelerated by uncaging $\mathrm{Ca}^{2+}$ in neighboring horizontal cells, suggesting that $\mathrm{Ca}^{2+}$ entering through CP-GluARs actually triggers release of a retrograde signal from horizontal cells. Similar effects of GluAR agonists on photoreceptor release were observed in salamander, zebrafish, and rabbit. The identity of the retrograde signaling molecule and the physiological role of the positive feedback remain to be determined.

CP-GluARs in horizontal cells appear to undergo a developmental change in their sensitivity to external polyamines (Osswald et al., 2007). Prior to eye opening (P14), $\mathrm{Co}^{2+}$ staining in horizontal cells is completely blocked by extracellularly applied polyamine toxins. In the few days following eye opening, however, horizontal cells become insensitive to polyamines and remain insensitive into adulthood (Figure 2A). Interestingly, this pharmacological shift is prevented by rearing mice in the dark, indicating that light-evoked activity triggers the change (Osswald et al., 2007). Although the mechanism underlying this phenomenon has not been identified, it may reflect a developmental increase in transmembrane GluAR regulatory protein (TARP) expression, which has been shown to 

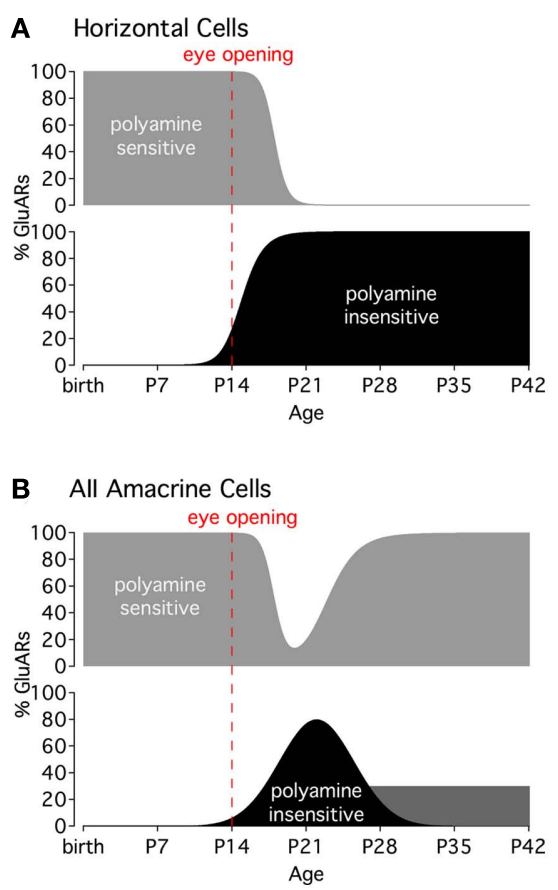

FIGURE 2 | Activity-dependent changes in CP-GluAR polyamine sensitivity. (A) CP-GluARs in horizontal cells become insensitive to polyamines around the time of eye opening (P14). (B) In All amacrine cells, CP-GluARs occupying the ON portion of the IPL recover polyamine sensitivity about 2 weeks after eye opening, whereas CP-GluARs in the OFF layer remain insensitive into adulthood (dark gray bar; Osswald et al., 2007). Graphs modified from Osswald et al. (2007).

diminish GluAR sensitivity to intracellular polyamines (Soto et al., 2007).

\section{CP-GLuARs PLAY MULTIPLE ROLES IN AMACRINE CELL SIGNALING}

The amacrine cell class comprises perhaps 30 different subtypes (MacNeil and Masland, 1998), only a small subset of which have been studied in any detail. In that select group, however, CP-GluARs appear to figure prominently. Both AII and A17 amacrine cells mediate synaptic input from RBCs through CPGluARs (Morkve et al., 2002; Singer and Diamond, 2003; Chávez et al., 2006; Figure 1C). Besides A17s, other GABAergic amacrine cells that contact RBCs also express CP-GluARs, in addition to $\mathrm{Ca}^{2+}$-impermeable GluARs (Chávez et al., 2010). By contrast, glycinergic amacrine cells that contact RBCs are driven by a combination of $\mathrm{Ca}^{2+}$-impermeable GluARs and NMDA receptors (GluNRs; Chávez and Diamond, 2008). It is tempting to speculate that GABAergic, typically wide-field amacrine cells express CP-GluARs and glycinergic, typically narrow-field amacrine cells express GluNRs. AIIs, glycinergic cells that express CP-GluARs synaptically (Singer and Diamond, 2003) and GluNRs extrasynaptically (Hartveit and Veruki, 1997), would be a notable exception to that tentative rule.

A17s provide reciprocal GABAergic feedback to RBC terminals (Hartveit, 1996, 1999; Singer and Diamond, 2003; Chávez et al.,
2006) that shapes visual signaling in the rod pathway (Nakatsuka and Hamasaki, 1985; Euler and Masland, 2000; Dong and Hare, 2003). A17 somata rest at the distal border of the IPL and project dozens of thin, unbranched dendrites deep into the IPL where they receive synaptic input from RBCs (Ellias and Stevens, 1980; Kolb and Nelson, 1983; Grimes et al., 2010). At the low end of the response range, GABA release from A17 synaptic varicosities occurs independently of $\mathrm{Ca}_{\mathrm{v}}$ channels, relying instead on CP-GluARs for $\mathrm{Ca}^{2+}$ influx (Chávez et al., 2006). $\mathrm{Ca}_{\mathrm{v}}$ channels are expressed on the varicosities, but their activation is limited by a $\mathrm{Ca}^{2+}$-activated $\mathrm{K}^{+}$conductance. Stronger stimulation overwhelms this $\mathrm{K}^{+}$conductance and recruits $\mathrm{Ca}_{\mathrm{v}}$ channels to trigger release (Grimes et al., 2009). The local coupling between CPGluARs and GABA release, along with the biophysical features of the A17 dendrites, enables the individual synaptic varicosities to operate independently (Grimes et al., 2010).

A specific role for CP-GluARs in AII amacrine cells is less clear. AIIs may rely on the relatively low affinity of CP-GluARs, rather than their $\mathrm{Ca}^{2+}$ permeability, to accurately encode vigorous multivesicular release from $\mathrm{RBC}$ ribbon synapses (Singer et al., 2004; Singer, 2007). RBC ribbons can unload their entire readily releasable vesicle pool in just a couple of milliseconds, yet AII EPSCs encode this release linearly, suggesting that the postsynaptic CP-GluARs are far from saturation (Singer and Diamond, 2006), likely a critical feature at an analog synapse.

As in horizontal cells, CP-GluARs in amacrine cells also undergo a light-dependent, developmental decrease in polyamine sensitivity (Osswald et al., 2007). The change in amacrine cells is short-lived, however, with polyamine sensitivity returning to preeye-opening levels in about 2 weeks (Figure 2B). An interesting exception occurs in AII dendrites occupying the OFF sublamina of the IPL, where CP-GluARs remain polyamine-insensitive into adulthood (Osswald et al., 2007; Figure 2B). The molecular mechanisms and functional implications of these developmental changes, which can differ between regions within individual cells, remains a very interesting, unanswered question.

\section{CP-GLUARs MAY CONTRIBUTE TO APOPTOSIS, EXCITOTOXICITY, AND PLASTICITY IN GCs}

Cell death plays an essential role in retinal development and disease (Valenciano et al., 2009). During the first 6 months of life, the human retina loses about 70\% of its GCs (Valenciano et al., 2009), and similar losses occur in the rat during the first two postnatal weeks (Galli-Resta and Ensini, 1996). In the adult retina, glaucoma, the most common cause of irreversible blindness, can claim $50 \%$ of the GC population (Kisiswa et al., 2010). As described below, recent work has implicated CP-GluARs in both apoptosis and excitotoxicity and has identified cellular mechanisms that may regulate the expression of CP-GluARs in the postsynaptic membrane.

The coincidence in CP-GluAR activity and GC cell death in the neonatal rat retina (Rorig and Grantyn, 1993; Leinders-Zufall et al., 1994; Zhang et al., 1995; Otori et al., 1998) suggests a potentially causal relationship between the two. One possibility is that increased CP-GluAR activation in the retina might trigger intracellular signals that impair the GC's ability to compete for trophic factors at its axon terminals in the thalamus during this period of "neurotrophic cell death" (Valenciano et al., 2009). Consistent with 
this scenario, CP-GluAR activation induces neurite retraction and eventual cell death in GCs in neonatal rat (Otori et al., 1998) and embryonic chick (Allcorn et al., 1996; Catsicas et al., 2001). While these reports indicated that $\mathrm{CP}$-GluARs initiate these processes, in mouse retina GluNRs expressed by Müller glial cells trigger expression of CP-GluARs and cell death in GCs through nuclear factor $\kappa \mathrm{B}$-mediated production of tumor necrosis factor $\alpha$ (LebrunJulien et al., 2009). Interestingly, rat GCs cultured in the absence of Müller glia are relatively resistant to NMDA excitotoxicity, despite ample expression of GluNRs (Ullian et al., 2004). Moreover, not all GCs may be equally susceptible to CP-GluAR-mediated toxicity: during the neonatal period of cell death, rat GCs exhibit a bimodal pattern of CP-GluAR activity: one group exhibits GluAR responses with low $\mathrm{Ca}^{2+}$ permeability, while another group exhibits very high $\mathrm{Ca}^{2+}$ permeability, based on electrophysiology, $\mathrm{Ca}^{2+}$ imaging, and $\mathrm{Co}^{2+}$ staining (Rorig and Grantyn, 1993; Leinders-Zufall et al., 1994; Zhang et al., 1995). Correlations between CP-GluAR function and specific GC subtypes have not yet been explored.

CP-GluAR activation leads to a reduction in CP-GluAR efficacy (Allcorn et al., 1996; Aizenman et al., 2002; Santiago et al., 2006), suggesting that CP-GluAR signaling may be controlled homeostatically. Such negative self-regulation could occur via CPGluAR-triggered increases in GluA2 protein expression, as shown in a cultured rat retina model of diabetic retinopathy (Santiago et al., 2006), or via activity-dependent increases in intracellular polyamine synthesis, like that induced in the tadpole optic tectum by visual stimulation (Aizenman et al., 2002). Recent experiments in cultured and intact mouse retina provide evidence for a third scenario in which activity induces subunit specific changes in GluAR trafficking to the cell surface (Xia et al., 2006, 2007). In retinal neurons (and elsewhere), surface expression of GluARs is maintained by a dynamic balance between ongoing receptor exocytosis and exocytosis, a process known as "constitutive cycling" (Xia et al., 2006). When endocytosis is blocked, the number of receptors on the cell surface increases due to ongoing exocytosis;

\section{REFERENCES}

Aizenman, C. D., Munoz-Elias, G., and Cline, H. T. (2002). Visually driven modulation of glutamatergic synaptic transmission is mediated by the regulation of intracellular polyamines. Neuron 34, 623-634.

Allcorn, S., Catsicas, M., and Mobbs, P. (1996). Developmental expression and self-regulation of $\mathrm{Ca} 2+$ entry via AMPA/KA receptors in the embryonic chick retina. Eur. J. Neurosci. 8, 2499-2510.

Catsicas, M., Allcorn, S., and Mobbs, P. (2001). Early activation of $\mathrm{Ca}(2+)$ permeable AMPA receptors reduces neurite outgrowth in embryonic chick retinal neurons. J. Neurobiol. 49, 200-211.

Chávez, A. E., Grimes, W. N., and Diamond, J. S. (2010). Mechanisms underlying lateral GABAergic feedback onto rod bipolar cells in rat retina. J. Neurosci. 30, 2223-2234.
Chávez, A. E., and Diamond, J. S. (2008). Diverse mechanisms underlie glycinergic feedback transmission onto rod bipolar cells in rat retina. J. Neurosci. 28, 7919-7928.

Chávez, A. E., Singer, J. H., and Diamond, J. S. (2006). Fast neurotransmitter release triggered by Ca influx through AMPA-type glutamate receptors. Nature 443, 705-708.

DeVries, S. H. (2000). Bipolar cells use kainate and AMPA receptors to filter visual information into separate channels. Neuron 28, 847-856.

Dong, C. J., and Hare, W. A. (2003). Temporal modulation of scotopic visual signals by A17 amacrine cells in mammalian retina in vivo. J. Neurophysiol. 89, 2159-2166.

Dreosti, E., Odermatt, B., Dorostkar, M. M., and Lagnado, L. (2009). A genetically encoded reporter of synaptic activity in vivo. Nat. Methods 6, 883-889.

conversely, blocking exocytosis decreases surface expression. The extent to which either modification changes surface expression is an indication of the rate of constitutive cycling. Xia et al. (2006) exploited this system to show that exogenous AMPA or synaptic activity decreases GluAR cycling, whereas the GluAR antagonist CNQX increased cycling. Cycling is regulated by physiological activity, as light deprivation increased cycling in ON GCs and decreased cycling in OFF GCs. These changes were observed following just $8 \mathrm{~h}$ of light deprivation, suggesting that GluAR trafficking is regulated during the 12-h light-dark cycle. Further experiments indicated that cycling receptors contain GluAR2 and that activity-induced decreases in cycling lead to an increase in surface GluAR2-containing, $\mathrm{Ca}^{2+}$-impermeable receptors (Xia et al., 2007). Synaptic quiescence, conversely, causes a reduction in surface GluAR2 and, therefore, an increase in the relative contribution of CP-GluARs. These results provide a mechanistic basis for activity-dependent regulation of CP-GluARs in retinal neurons and suggest that retinal synapses, contrary to conventional wisdom, may possess the capacity for long-term plasticity.

\section{CONCLUSION}

This review highlighted recent work implicating CP-GluARs in several aspects of retinal development, function, and disease. There is still much to learn, however, about the roles for synaptic CPGluAR signaling in visual processing, as well as the mechanisms regulating CP-GluAR expression and trafficking in the retina. Improved pharmacological tools (Magazanik et al., 1997), recently developed genetically encoded synaptic $\mathrm{Ca}^{2+}$ indicators (Dreosti et al., 2009; Tian et al., 2009), and optogenetic approaches (Greenberg et al., 2011) promise to yield further insights into these issues.

\section{ACKNOWLEDGMENTS}

This work was supported by the NINDS Intramural Research Program.

Eliasof, S., and Jahr, C. E. (1997). Rapid AMPA receptor desensitization in catfish cone horizontal cells. Vis. Neurosci. 14, 13-18.

Ellias, S. A., and Stevens, J. K. (1980). The dendritic varicosity: a mechanism for electrically isolating the dendrites of cat retinal amacrine cells? Brain Res. 196, 365-372.

Euler, T., and Masland, R. H. (2000). Light-evoked responses of bipolar cells in a mammalian retina. J. Neurophysiol. 83, 1817-1829.

Galli-Resta, L., and Ensini, M. (1996). An intrinsic time limit between genesis and death of individual neurons in the developing retinal ganglion cell layer. J. Neurosci. 16, 2318-2324.

Greenberg, K. P., Pham, A., and Werblin, F. S. (2011). Differential targeting of optical neuromodulators to ganglion cell soma and dendrites allows dynamic control of centersurround antagonism. Neuron 69, 713-720.
Grimes, W. N., Li, W., Chavez, A. E., and Diamond, J. S. (2009). BK channels modulate pre- and postsynaptic signaling at reciprocal synapses in retina. Nat. Neurosci. 12, 585-592.

Grimes, W. N., Zhang, J., Graydon, C. W., Kachar, B., and Diamond, J. S. (2010). Retinal parallel processors: more than 100 independent microcircuits operate within a single interneuron. Neuron 65, 873-885.

Hartveit, E. (1996). Membrane currents evoked by ionotropic glutamate receptor agonists in rod bipolar cells in the rat retinal slice preparation. J. Neurophysiol. 76, 401-422.

Hartveit, E. (1999). Reciprocal synaptic interactions between rod bipolar cells and amacrine cells in the rat retina. J. Neurophysiol. 81, 2923-2936.

Hartveit, E., and Veruki, M. L. (1997) AII amacrine cells express functional NMDA receptors. Neuroreport 8, 1219-1223 
Hirano, A. A., Brandstatter, J. H., and Brecha, N. C. (2005). Cellular distribution and subcellular localization of molecular components of vesicular transmitter release in horizontal cells of rabbit retina. J. Comp. Neurol. $488,70-81$.

Hirasawa, H., and Kaneko, A. (2003). $\mathrm{pH}$ changes in the invaginating synaptic cleft mediate feedback from horizontal cells to cone photoreceptors by modulating $\mathrm{Ca} 2+$ channels. J. Gen. Physiol. 122, 657-671.

Huang, S. Y., and Liang, P. J. (2005). Ca2+-permeable and Ca2+impermeable AMPA receptors coexist on horizontal cells. Neuroreport $16,263-266$.

Jackman, S. L., Babai, N., Chambers, J. J., Thoreson, W. B., and Kramer, R. H. (2011). A positive feedback synapse from retinal horizontal cells to cone photoreceptors. PLoS Biol. 9, e1001057. doi: 10.1371/journal.pbio. 1001057

Kamermans, M., Fahrenfort, I., Schultz, K., Janssen-Bienhold, U., Sjoerdsma, T., and Weiler, R. (2001). Hemichannel-mediated inhibition in the outer retina. Science 292, 1178-1180.

Kisiswa, L., Dervan, A. G., Albon, J., Morgan, J. E., and Wride, M. A. (2010). Retinal ganglion cell death postponed: giving apoptosis a break? Ophthalmic Res. 43, 61-78.

Kolb, H., and Nelson, R. (1983). Rod pathways in the retina of the cat. Vision Res. 23, 301-312.

Kreitzer, M. A., Birnbaum, A. D., Qian, H., and Malchow, R. P. (2009). Pharmacological characterization, localization, and regulation of ionotropic glutamate receptors in skate horizontal cells. Vis. Neurosci. 26, 375-387.

Lebrun-Julien, F., Duplan, L., Pernet, V., Osswald, I., Sapieha, P., Bourgeois, P., Dickson, K., Bowie, D., Barker, P. A., and Di Polo, A. (2009). Excitotoxic death of retinal neurons in vivo occurs via a non-cellautonomous mechanism. J. Neurosci. 29, 5536-5545.

Leinders-Zufall, T., Rand, M. N., Waxman, S. G., and Kocsis, J. D. (1994). Differential role of two $\mathrm{Ca}(2+)$ permeable non-NMDA glutamate channels in rat retinal ganglion cells: kainate-induced cytoplasmic and nuclear $\mathrm{Ca} 2+$ signals. J. Neurophysiol. 72, 2503-2516.

MacNeil, M. A., and Masland, R. H. (1998). Extreme diversity among amacrine cells: implications for function. Neuron 20, 971-982.

Magazanik, L. G., Buldakova, S. L., Samoilova, M. V., Gmiro, V. E., Mellor, I. R., and Usherwood, P. N. (1997). Block of open channels of recombinant AMPA receptors and native AMPA/kainate receptors by adamantane derivatives. J. Physiol. (Lond.) 505(Pt 3), 655-663.

Morkve, S. H., Veruki, M. L., and Hartveit, E. (2002). Functional characteristics of non-NMDA-type ionotropic glutamate receptor channels in AII amacrine cells in rat retina. J. Physiol. (Lond.) 542, 147-165.

Nakatsuka, K., and Hamasaki, D. I. (1985). Destruction of the indoleamine-accumulating amacrine cells alters the ERG of rabbits. Invest. Ophthalmol. Vis. Sci. 26, 1109-1116.

Osswald, I. K., Galan, A., and Bowie, D. (2007). Light triggers expression of philanthotoxin-insensitive Ca2+permeable AMPA receptors in the developing rat retina. J. Physiol. (Lond.) 582, 95-111.

Otori, Y., Wei, J. Y., and Barnstable, C. J. (1998). Neurotoxic effects of low doses of glutamate on purified rat retinal ganglion cells. Invest. Ophthalmol. Vis. Sci. 39, 972-981.

Parsons, T. D., and Sterling, P. (2003). Synaptic ribbon. Conveyor belt or safety belt? Neuron $37,379-382$.

Pruss, R. M., Akeson, R. L., Racke, M. M., and Wilburn, J. L. (1991). Agonist-activated cobalt uptake identifies divalent cation-permeable kainate receptors on neurons and glial cells. Neuron 7, 509-518.

Raman, I. M., and Trussell, L. O. (1992). The kinetics of the response to glutamate and kainate in neurons of the avian cochlear nucleus. Neuron 9, 173-186.

Rivera, L., Blanco, R., and de la Villa, P. (2001). Calcium-permeable glutamate receptors in horizontal cells of the mammalian retina. Vis. Neurosci. 18, 995-1002.

Rorig, B., and Grantyn, R. (1993). Rat retinal ganglion cells express $\mathrm{Ca}(2+)$-permeable non-NMDA glutamate receptors during the period of histogenetic cell death. Neurosci. Lett. 153, 32-36.

Sakai, H. M., and Naka, K. (1986). Synaptic organization of the cone horizontal cells in the catfish retina. J. Comp. Neurol. 245, 107-115.
Santiago, A. R., Rosa, S. C., Santos, P. F., Cristovao, A. J., Barber, A. J., and Ambrosio, A. F. (2006). Elevated glucose changes the expression of ionotropic glutamate receptor subunits and impairs calcium homeostasis in retinal neural cells. Invest. Ophthalmol. Vis. Sci. 47, 4130-4137.

Sasaki, T., and Kaneko, A. (1996). L-Glutamate-induced responses in OFF-type bipolar cells of the cat retina. Vision Res. 36, 787-795.

Singer, J. H. (2007). Multivesicular release and saturation of glutamatergic signalling at retinal ribbon synapses. J. Physiol. (Lond.) 580, 23-29.

Singer, J. H., and Diamond, J. S. (2003). Sustained $\mathrm{Ca} 2+$ entry elicits transient postsynaptic currents at a retinal ribbon synapse. J. Neurosci. 23, 10923-10933.

Singer, J. H., and Diamond, J. S. (2006). Vesicle depletion and synaptic depression at a mammalian ribbon synapse. J. Neurophysiol. 95, 3191-3198.

Singer, J. H., Lassova, L., Vardi, N., and Diamond, J. S. (2004). Coordinated multivesicular release at a mammalian ribbon synapse. Nat. Neurosci. 7, 826-833.

Soto, D., Coombs, I. D., Kelly, L., Farrant, M., and Cull-Candy, S. G. (2007). Stargazin attenuates intracellular polyamine block of calciumpermeable AMPA receptors. Nat. Neurosci. 10, 1260-1267.

Sugioka, M., Fukuda, Y., and Yamashita, M. (1998). Development of glutamate-induced intracellular $\mathrm{Ca} 2+$ rise in the embryonic chick retina. J. Neurobiol. 34, 113-125.

Sun, Y., Jiang, X. D., Liu, X., Gong, H. Q., and Liang, P. J. (2010). Synaptic contribution of $\mathrm{Ca} 2+-$ permeable and Ca2+-impermeable AMPA receptors on isolated carp retinal horizontal cells and their modulation by Zn2+. Brain Res. 1317, 60-68.

Tian, L., Hires, S. A., Mao, T., Huber, D., Chiappe, M. E., Chalasani, S. H., Petreanu, L., Akerboom, J., McKinney, S. A., Schreiter, E. R., Bargmann, C. I., Jayaraman, V., Svoboda, K., and Looger, L. L. (2009). Imaging neural activity in worms, flies and mice with improved GCaMP calcium indicators. Nat. Methods 6, 875-881.

Ullian, E. M., Barkis, W. B., Chen, S., Diamond, J. S., and Barres, B. A. (2004). Invulnerability of retinal ganglion cells to NMDA excitotoxicity. Mol. Cell. Neurosci. 26, 544-557.

Valenciano, A. I., Boya, P., and de la Rosa, E. J. (2009). Early neural cell death: numbers and cues from the developing neuroretina. Int. J. Dev. Biol. 53 , 1515-1528

Vaney, D. I., Gynther, I. C., and Young, H. M. (1991). Rod-signal interneurons in the rabbit retina: 2. AII amacrine cells. J. Comp. Neurol. 310, 154-169.

Vessey, J. P., Stratis, A. K., Daniels, B. A. Da Silva, N., Jonz, M. G., Lalonde, M. R., Baldridge, W. H., and Barnes, S. (2005). Proton-mediated feedback inhibition of presynaptic calcium channels at the cone photoreceptor synapse. J. Neurosci. 25, 4108-4117.

Wassle, H., Puller, C., Muller, F., and Haverkamp, S. (2009). Cone contacts, mosaics, and territories of bipolar cells in the mouse retina. $J$. Neurosci. 29, 106-117.

Xia, Y., Carroll, R. C., and Nawy, S. (2006). State-dependent AMPA receptor trafficking in the mammalian retina. J. Neurosci. 26, 5028-5036.

Xia, Y., Nawy, S., and Carroll, R. C. (2007). Activity-dependent synaptic plasticity in retinal ganglion cells. $J$. Neurosci. 27, 12221-12229.

Zhang, D., Sucher, N. J., and Lipton, S. A. (1995). Co-expression of AMPA/kainate receptor-operated channels with high and low $\mathrm{Ca} 2+$ permeability in single rat retinal ganglion cells. Neuroscience 67 , 177-188.

Conflict of Interest Statement: The author declares that the research was conducted in the absence of any commercial or financial relationships that could be construed as a potential conflict of interest.

Received: 05 August 2011; paper pending published: 29 August 2011; accepted: 07 September 2011; published online: 26 September 2011.

Citation: Diamond JS (2011) Calciumpermeable AMPA receptors in the retina. Front. Mol. Neurosci. 4:27. doi: 10.3389/fnmol.2011.00027

Copyright (c) 2011 Diamond. This is an open-access article subject to a nonexclusive license between the authors and Frontiers Media SA, which permits use, distribution and reproduction in other forums, provided the original authors and source are credited and other Frontiers conditions are complied with. 